\title{
Epithelioid sarcoma: A case series of three different presentations
}

\author{
Dhaval Jetly, Annapoorani Varadarajan, Kinnari S Naik, Priya Patel \\ Department of Pathology, Gujarat Cancer \& Research Institute, Ahmedabad, India
}

Received: April 16, 2017

DOI: $10.5430 /$ crcp.v4n3p1

\author{
Accepted: May 17, 2017 \\ Online Published: June 8, 2017
}

\begin{abstract}
Background: Epithelioid sarcoma is a rare malignancy that presents diagnostic difficulties.

Cases: We report three cases of epithelioid sarcoma with different presentations and clinical course. One patient had a classicaltype epithelioid sarcoma while rest two suffered from the rarer proximal-type. All three underwent surgical excision while two of them also had postoperative adjuvant therapy. The diagnostic challenges and the final outcome has been discussed in detail.

Conclusion: The diagnosis of epithelioid sarcoma needs a high index of clinical suspicion and immunohistochemistry is extremely valuable. Adequacy of index surgery affects the ultimate prognosis.
\end{abstract}

Key Words: Epithelioid sarcoma, Distal type, Proximal type, Classical type, Immunohistochemistry

\section{INTRODUCTION}

Epithelioid sarcoma (ES) is an uncommon, slow growing soft tissue neoplasm that was first reported by Enzinger in 1970. ${ }^{[1]}$ It accounts for less than $1 \%$ of all soft tissue sarcomas. ${ }^{[2]}$ The typical location is distal portion of the extremities, especially fingers, hand and forearm (distal/classical-type). ${ }^{[3]}$ Adolescents and young adults are commonly affected. An aggressive type of ES, namely "proximal/axial" type, arises from soft tissues of pelvis, perineum and proximal extremities. ${ }^{[4]}$ This type was identified by Guillou et al. in 1997 and tends to affect older adults as compared to classical-type. ${ }^{[5]}$

In this case series, we report the myriad presentations of ES and their specific histopathological and immunohistochemistry features.

\section{Case presentation}

\subsection{Case 1}

A thirty years old male presented with multiple, nodular, painless lesions over right wrist since 1 month. He was previously operated for similar complaints at a peripheral centre 4 months before. Examination revealed three subcutaneous nodules each measuring $1 \mathrm{~cm} \times 1 \mathrm{~cm}$ over the dorsal aspect of right wrist. The nodules were firm in consistency and did not involve the underlying tendon or bone. Old, healed surgical scar was noted at the same site. No axillary lymph nodes were palpable.

Magnetic resonance imaging of right wrist revealed three well defined, lobulated, heterogenous enhancing focal lesions suggestive of recurrence. Slides from previous surgery were reviewed which revealed a "malignant, undifferentiated tumour with epithelial differentiation" (see Figure 1). On

\footnotetext{
* Correspondence: Annapoorani Varadarajan; Email: poorani.v.rajan@ gmail.com; Address: Department of Pathology, Gujarat Cancer \& Research Institute, Ahmedabad 380016, India. 
further IHC (Immunohistochemistry) characterisation, the tissue was positive for AE1, Vimentin and CD99 while it was negative for CK7, TTF-1, CK20 and Calponin (see Figure 2). A diagnosis of classical-type ES was made and patient underwent wide local excision. Histopathological examination revealed recurrence of ES with negative margins.

Patient was asymptomatic for 5 months, after which he developed a second recurrence. He was subjected again to wide local excision again and the specimen revealed an infiltrative growth grossly and recurrent ES microscopically. By now, patient had developed multiple lymph node enlargements in bilateral axilla on CT examination. Patient received adjuvant post-operative radiotherapy of $50 \mathrm{~Gy}$ in 20 fractions. He continued to remain asymptomatic until last follow-up of 9 months following final surgical procedure.

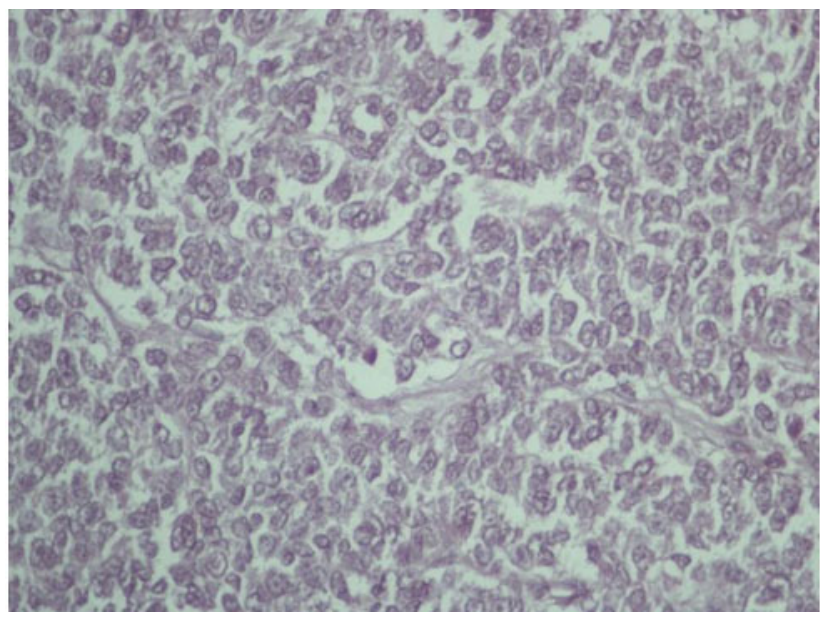

Figure 1. H\&E preparation of Case 1(see text) showing large malignant cells with epithelioid features (H\&E, 40×)

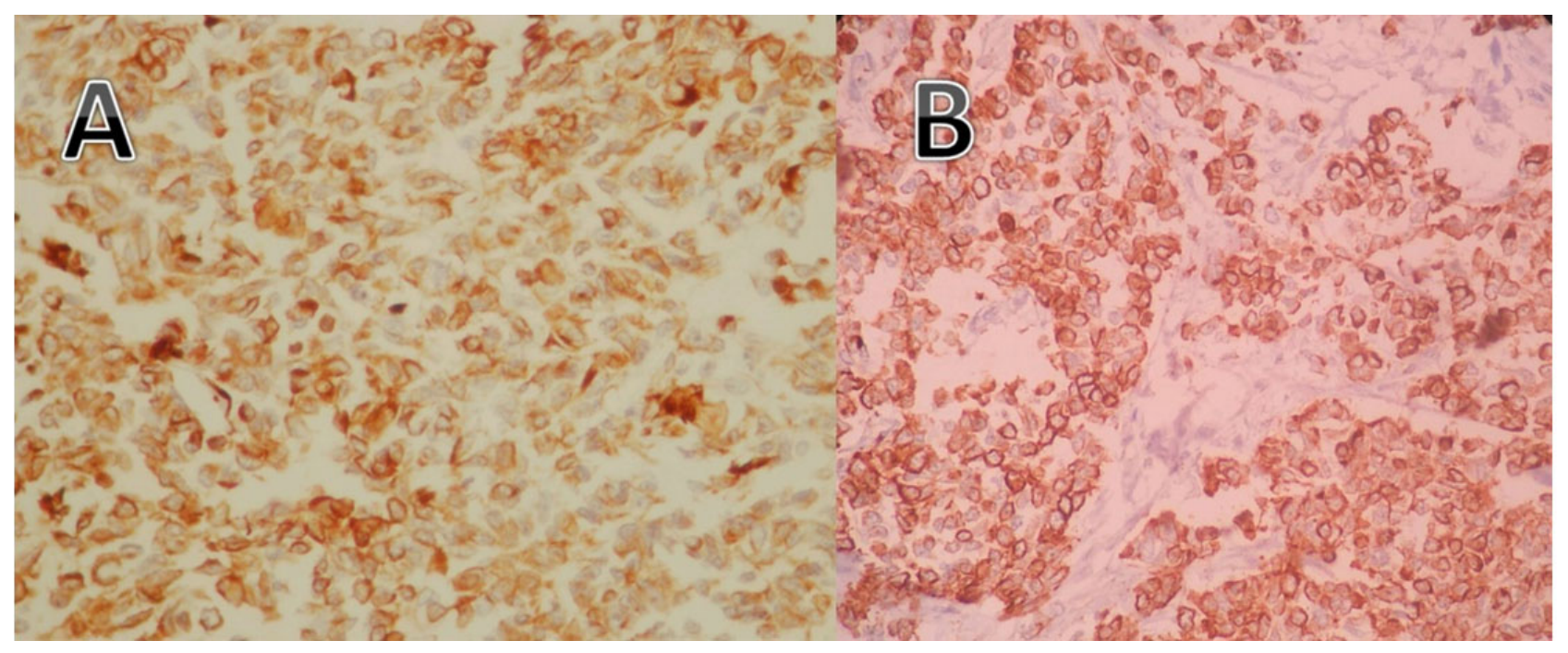

Figure 2. Immunohistochemistry preparation of Case 1

A) Vimentin positivity $(40 \times)$; B) $A E 1$ positivity $(40 \times)$

\subsection{Case 2}

A 35-year-old female, who had undergone a left above elbow amputation 5 years ago, presented with recurrent swelling at amputation stump. The amputation procedure was performed for malignancy at a peripheral centre. Histopathology reports were not available. On examination, she had an irregular, well defined lesion at distal part of amputation stump measuring $11 \mathrm{~cm} \times 10 \mathrm{~cm}$. Although the lesion was predominantly situated in the subcutaneous plane, it had involved the underlying muscle as well. Magnetic resonance imaging showed a large lesion circumferentially involving the site of amputation and extending into the muscular compartment.

Fine needle aspiration cytology (FNAC) was confirmatory of a malignant etiology. With the diagnosis of recurrent malignancy, patient underwent left shoulder disarticulation. Gross examination of the specimen demonstrated an infiltrative nodular growth of left arm having grey white cut section with haemorrhagic areas. Microscopy revealed an epithelioid sarcoma involving soft tissues of left arm in muscular plane with all cut ends, skin and humerus free of tumour (see Figure 3). Tumour giant cells were present and the lesion was given histologic grade II as per FNC LCC system. Immunohistochemistry confirmed the diagnosis of epithelioid sarcoma. Vimentin, cyclin D1 and EMA (Epithelial Membrane Antigen) were positive while Desmin, Actin, AE 1, HMB 45 and CD-34 were negative (see Figure 4).

This patient did not receive any postoperative adjuvant therapy and she remained asymptomatic at final follow-up of 6 months. 


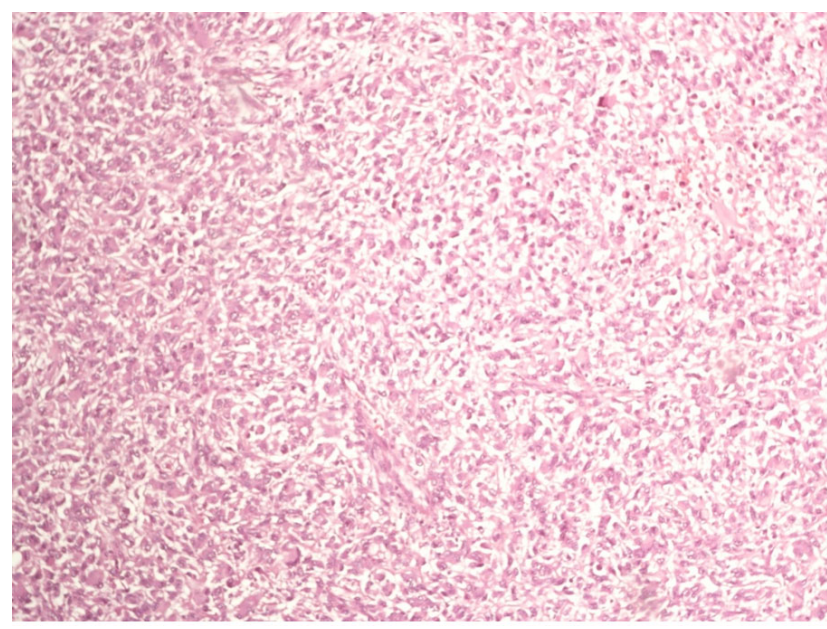

Figure 3. H\&E preparation of Case 2 showing sheets of epithelioid cells with marked cytologic atypia, eccentric vesicular nucleus and abundant eosinophilic cytoplasm (H\&E, 40×)

\subsection{Case 3}

A seventeen years old female presented with painful mass over vulval region since a month. Examination revealed a $5 \mathrm{~cm} \times 5 \mathrm{~cm}$, irregular mass situated over the right side of vulva. This mass was slightly tender to touch and firm in consistency. Inguinal examination showed multiple, firm and mobile lymph nodes bilaterally.

Radiographic examination did not demonstrate any involvement of the underlying pubic bones. On CT scan, patient was found to have a necrotic, infiltrative mass lesion involving lateral aspect of fat pad of vulva with skin and underlying pectineus muscle infiltration and necrotic inguinal lymphadenopathy. The overall appearance was suggestive of a neoplastic lesion with metastatic lymphadenopathy. Slides of FNAC from inguinal nodes performed at a peripheral centre were reviewed. They were positive for malignancy with appearances suggestive of either a sarcoma with epitheloid features or a malignant melanoma.

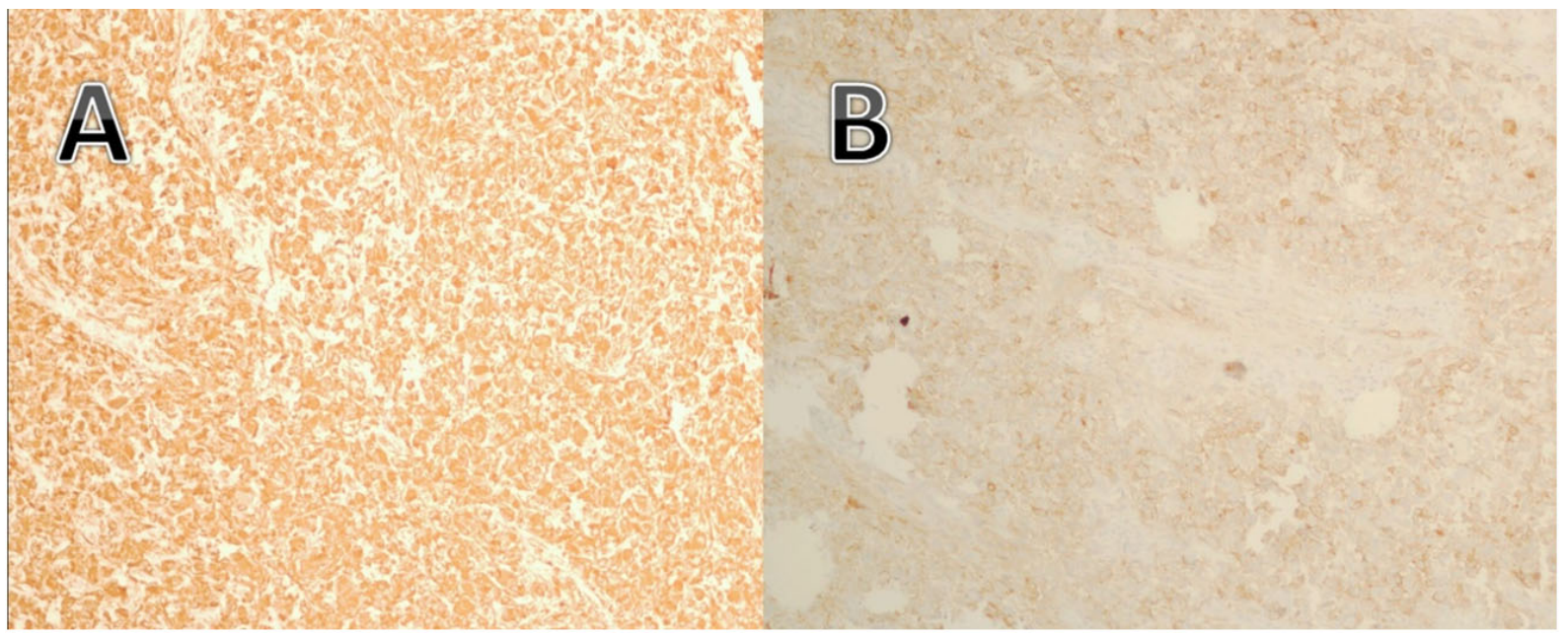

Figure 4. Immunohistochemistry preparation of Case 2

A) Vimentin positivity $(10 \times)$; B) EMA positivity $(10 \times)$

Patient underwent wide local excision of groin and vulva. Grossly, the specimen showed an infiltrative growth with grey white nodular areas on cut section and several lymph nodes were identified. Microscopically, the lesion was reported as poorly differentiated malignant tumour involving the vulva with base of resection and skin margins free of tumour (see Figure 5). Fifteen out of 21 lymph nodes showed presence of metastases. IHC revealed a proximal-type epithelioid sarcoma of vulva. The markers AE 1, EMA, Vimentin, CD 34 and CA125 were positive (see Figure 6). The markers, S-100, HMB-45, Melan-A, Desmin, MyoD-1 and myoglobin were found to be negative which was helpful in excluding malignant melanoma.
This patient received postoperative radiotherapy and she remained asymptomatic at final follow-up of 6 months.

\section{Discussion}

Epithelioid sarcoma is a rare, high grade, soft tissue tumor with high propensity for local recurrence, regional lymph node involvement and distant metastasis. The classical-type most commonly affects the distal extremities. It never affects the trunk, genitals and head and neck regions. This type has a distinct nodular arrangement of eosinophilic spindle and epithelioid cells and has a tendency to undergo central degeneration and necrosis. This appearance can be easily mistaken for a granuloma or benign necrobiotic process such as a rheumatoid nodule. ${ }^{[6]}$ The cellular elements range from 
large ovoid or polygonal cells with deeply eosinophilic cytoplasm to plump spindle shaped cells. Lesions located or extending into the dermis often ulcerate through the skin and may simulate an ulcerating squamous cell carcinoma, especially because of the pronounced epithelioid appearance and eosinophilia of tumor cells. Usually, epithelioid and spindle cells merge imperceptibly, and there is no biphasic or pseudo-glandular pattern as one encounters in synovial sarcoma. Our first patient underwent inadequate surgical excision at a peripheral centre leading to multiple recurrences. This emphasises the need to establish a histopathological diagnosis before undertaking surgical procedure on any mass lesion including those which are benign "looking".

Epithelioid sarcoma is known to propagate along tendon and nerve sheaths and fascial planes. Microscopically, they might demonstrate perivascular and perineural infiltration. This tumour can recur even after prolonged symptom free interval as evidenced in our second patient. The overall recurrence rate is as high as $80 \%$ at 10 years. The rate depends mainly on the adequacy of initial resection. Our second patient un- derwent a radical procedure (shoulder disarticulation) hence she did not require adjuvant therapy.

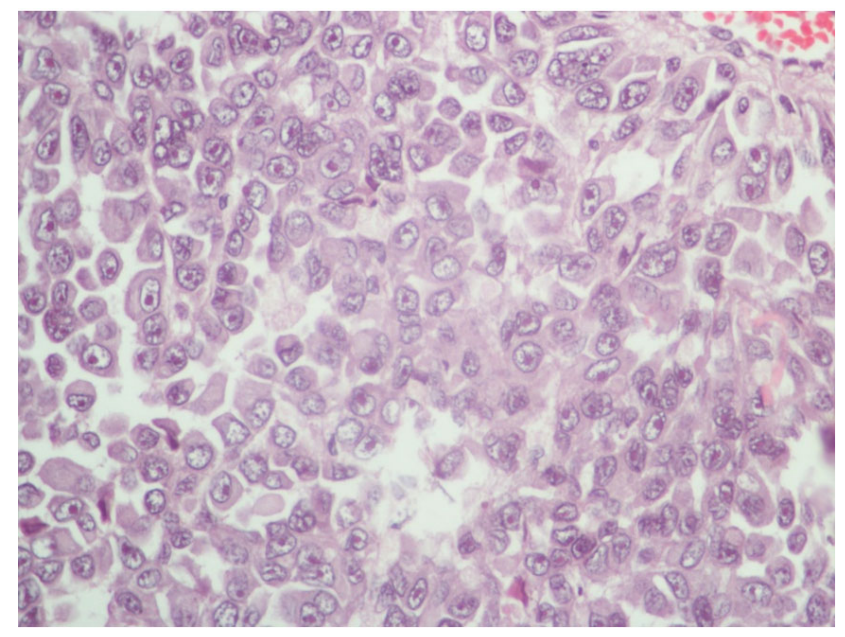

Figure 5. H\&E preparation of Case 3 showing large epithelioid cells with marked cytologic atypia, prominent nucleoli and abundant eosinophilic cytoplasm (H\&E, 40×)

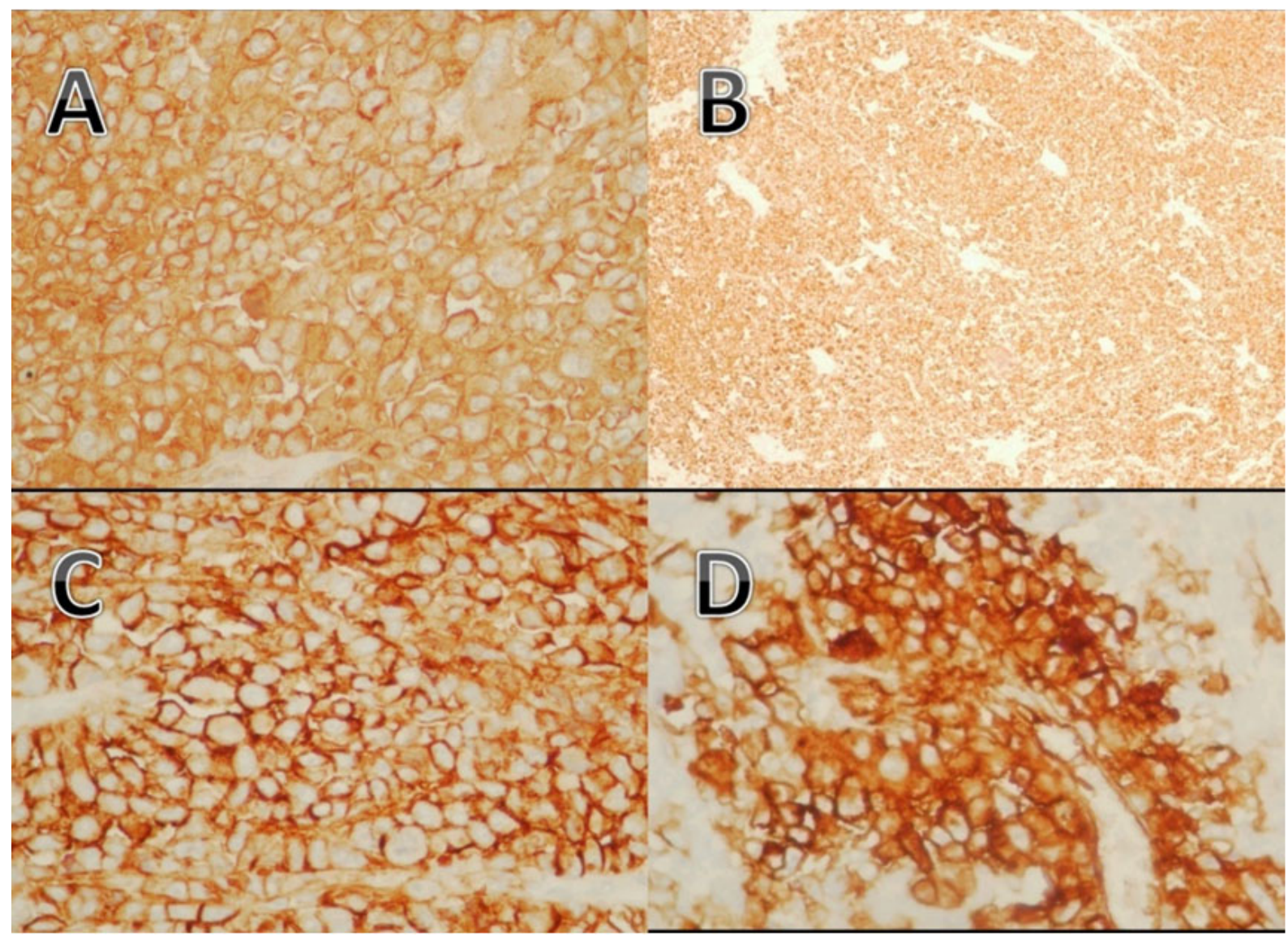

Figure 6. Immunohistochemistry preparation of Case 3

A) EMA positivity $(40 \times)$; B) AE 1 positivity (10×); C) CA-125 positivity (40×); D) CD 34 positivity $(40 \times)$ 
Jawad et al studied the SEER database and found the overall survival of ES to be $68 \%$ at 5 years and $61 \%$ at 10 years. ${ }^{[7]}$ Asano et al. reported $30 \%$ local recurrence rate with the median interval between surgery and first local recurrence as 25 months. ${ }^{[8]}$ The distant metastasis rate varies between $40 \%$ and $57 \%$. The proximal-type ES is more aggressive than its classical counterpart. It accounts for only one third of the total share of ES. ${ }^{[9]}$ Although the literature reports an older age group in affected patients, our patient was just 17 years of age at presentation. ${ }^{[10]}$ It typically shows large cells with prominent nucleoli, marked cytological atypia and intracytoplasmic hyaline inclusions. ${ }^{[11]}$ These together impart a "RHABDOID" appearance to this variant. Though tumour necrosis occurs, it seldom results in granuloma like appearance unlike a "classical" variant. The aggressive nature of the "Proximal" variant is very well demonstrated in our third patient who had skin and muscle infiltration with necrotic lymphadenopathy. This type is associated with multimodal therapy resistance and early tumour related deaths.

Table 1. Comparision of immunohistochemical marker expression among common differential diagnosis of epithelioid sarcoma

\begin{tabular}{|c|c|c|c|c|c|c|c|}
\hline $\begin{array}{l}\text { IHC } \\
\text { Marker }\end{array}$ & $\begin{array}{l}\text { Epithelioid } \\
\text { sarcoma }\end{array}$ & $\begin{array}{l}\text { Epithelioid malignant } \\
\text { peripheral nerve } \\
\text { sheath tumors }\end{array}$ & $\begin{array}{l}\text { Epithelioid } \\
\text { hemangio } \\
\text { endothelioma }\end{array}$ & $\begin{array}{l}\text { Langerhan } \\
\text { cell } \\
\text { sarcoma }\end{array}$ & $\begin{array}{l}\text { Mammary } \\
\text { sarcoma }\end{array}$ & $\begin{array}{l}\text { Malignant } \\
\text { melanoma }\end{array}$ & $\begin{array}{l}\text { Epithelioid } \\
\text { rhabdomyo } \\
\text {-sarcoma }\end{array}$ \\
\hline Vimentin & +++ & & & - & ++ & & - \\
\hline $\begin{array}{l}\text { Cytokeratin } \\
(\mathrm{AE} 1)\end{array}$ & +++ & $+/-$ & - & - & - & & - \\
\hline EMA & +++ & $+/-$ & & - & - & & - \\
\hline S-100 & - & +++ & & +++ & & +++ & \\
\hline CD 31 & - & & +++ & & & & \\
\hline CD 1a & - & & & +++ & & & \\
\hline Langerin & - & & & +++ & & & \\
\hline CD 10 & - & & & & +++ & & \\
\hline HMB 45 & $+/-$ & & & & & +++ & \\
\hline CD 34 & $+/-$ & & & & & - & \\
\hline CA 125 & $+/-$ & & & & & ++ & \\
\hline Desmin & - & & & & & & +++ \\
\hline Myogenin & - & & & & & & +++ \\
\hline Myo D1 & - & & & & & & +++ \\
\hline
\end{tabular}

Immunohistochemistry proved extremely reliable in all three of our patients. Immunohistochemical studies on ES show immunoreactivity for Vimentin, Cytokeratin, and EMA. S100 and CD31 are Negative, while Desmin, CA125 and CD34 are positive in some cases. ${ }^{[11]}$ Here, the epithelial marker Vimentin was positive in all of them while AE 1 and EMA were positive in two. The battery of markers to be tested was chosen based on clinical picture and microscopic appearance to rule out other differential diagnosis (see Table 1). Langerhans cell sarcoma (LCS) and Mammary sarcoma (MS) may mimic "Proximal" variant of epithelioid sarcoma. However, in LCS the tumor cells are positive for CD1a, S-100 Protein and Langerin whereas MS tumor cells show positivity for CD 10 and vimentin. Both these tumors demonstrate negativity for epithelial and other myoepithelial markers. ${ }^{[12]}$ Epitheloid malignant peripheral nerve sheath tumors (MPNSTs) might demonstrate immunoreactivity for cytokeratin and EMA occasionally, but majority of MPNSTs show diffuse and strong reactivity for S-100 Protein. ${ }^{[13]}$ Similarly, malignant melanomas are typically positive for S-100 and HMB-45. This emphasises the importance of suspecting this rare entity in relevant cases.

\section{Conclusion}

Epithelioid sarcoma is a great masquerader and a high index of suspicion is needed to diagnose it. Immunohistochemistry is an extremely useful tool to confirm the diagnosis. Prognosis is dismal and adequacy of the initial surgical procedure and early detection plays a crucial role and is the most important predictor of recurrence. Proximal type can present in trunk including vulva and is more aggressive than the classical type. 


\section{REFERENCES}

[1] Enzinger FM. Epithelioid sarcoma. A sarcoma simulating a granuloma or a carcinoma. Cancer. 1970; 26(5): 1029 1041. https://doi.org/10.1002/1097-0142(197011)26: 5<1029: :AID-CNCR2820260510>3.0.CO;2-R

[2] Armah HB, Parwani AV. Epithelioid sarcoma. Arch Pathol Lab Med. 2009 May; 133(5): 814-9. PMid: 19415960.

[3] Karagkounis G, Argyrakos T, Charkiolakis G, et al. A case of distal epithelioid sarcoma of the thumb expressing podoplanin, TLE1 and Ca 125. Case Rep Pathol [Internet]. 2013 [cited 2017 Mar 3]; 2013 Available from: https://www.hindawi.com/journals/cripa /2013/312786/abs/

[4] Echchaoui A, Sadrati Y, Elbir Y, et al. Proximal-type epithelioid sarcoma: a new case report and literature review. Pan Afr Med J [Internet]. 2016 [cited 2017 Mar 3]; 24(1). Available from: http: //www .ajol.info/index.php/pamj/article/view/144247

[5] Guillou L, Wadden C, Coindre JM, et al. " Proximal-type" Epithelioid Sarcoma, a Distinctive Aggressive Neoplasm Showing Rhabdoid Features: Clinicopathologic, Immunohistochemical, and Ultrastructural Study of a Series. Am J Surg Pathol. 1997; 21(2): 130-146. PMid: 9042279. https ://doi .org/10.1097/00000478-19970 2000-00002

[6] Bhama BA, Dhir RS, Pandit AA. Epithelioid sarcoma of the upper extremity (a case report). J Postgrad Med. 1987; 33(3): 140. PMid: 3430402.

[7] Jawad MU, Extein J, Min ES, et al. Prognostic Factors for Survival in Patients with Epithelioid Sarcoma: 441 Cases from the
SEER Database. Clin Orthop. 2009 Nov; 467(11): 2939-48. PMid: 19224301. https://doi.org/10.1007/s11999-009-0749-2

[8] Asano N, Yoshida A, Ogura K, et al. Prognostic Value of Relevant Clinicopathologic Variables in Epithelioid Sarcoma: A MultiInstitutional Retrospective Study of 44 Patients. Ann Surg Oncol. 2015 Aug 1; 22(8): 2624-32. PMid: 25663591. https://doi.or g/10.1245/s10434-014-4294-1

[9] Suárez-Zamora DA, Barrera-Herrera LE, Rodríguez-Urrego PA, et al. Proximal-Type Epithelioid Sarcoma: Report of an Unusual Case in the Uterine Cervix. Int J Surg Pathol. 2017 Feb 1. https : //doi.org/10.1177/1066896917696744

[10] Santos LM dos, Nogueira L, Matsuo CY, et al. Proximal-type epithelioid sarcoma-Case report. An Bras Dermatol. 2013; 88(3): 444-447. PMid: 23793215. https://doi.org/10.1590/abd1806-4841. 20131922

[11] Hasegawa T, Matsuno Y, Shimoda T, et al. Proximal-type epithelioid sarcoma: a clinicopathologic study of 20 cases. Mod Pathol. 2001; 14(7): 655-663. PMid: 11454997. https://doi.org/10.1038/ modpathol. 3880368

[12] Yang GZ, Li J, Jin H, et al. Is mammary not otherwise specified-type sarcoma with CD10 expression a distinct entity? A rare case report with immunohistochemical and ultrastructural study. Diagn Pathol. 2013; 8(1): 14. PMid: 23356903. https ://doi.org/10.1186/17 46-1596-8-14

[13] Iwata J, Fletcher CD. Immunohistochemical detection of cytokeratin and epithelial membrane antigen in leiomyosarcoma: a systematic study of 100 cases. Pathol Int. 2000; 50(1): 7-14. PMid: 10692172 https://doi.org/10.1046/j.1440-1827.2000.01001.x 